\title{
Pensar em opostos: a crítica cultural de Friedrich Schiller e Friedrich Nietzsche ${ }^{*}$
}

\author{
Arno Gimber**
}

Resumo: O entendimento de Friedrich Nietzsche sobre Friedrich Schiller é bem conhecido e culmina em 1888, na desqualificação que se tem com "Schiller: ou o trompetista moral de Säckingen". Mas é sabido que suas considerações são contraditórias, mudando com frequência nas diferentes etapas de sua vida produtiva. A monografia de Nicholas Martin (1996) marca um ponto de viragem no que diz respeito a este tema, refutando a disseminada compreensão de que somente o jovem Nietzsche teria experimentado admiração por Schiller, depois vindo a assumir distância cada vez maior. A dívida de Nietzsche para com Schiller, segundo Martin, é constante, e manifesta-se sobretudo em sua recepção das cartas estéticas. $\mathrm{O}$ que se pretende fazer ver aqui, seguindo a tradição de Wolfgang Riedel (2011), é que o ensaio Sobre a poesia ingênua e sentimental [Über naive und sentimentalische Dichtung] é tão ou mais importante neste contexto sobretudo quando dirigimos nosso enfoque para o contexto da crítica cultural. Várias declarações de Nietzsche, por exemplo, formulada em 1870, “não estou em condições de empregar essa terminologia esplendorosamente schilleriana para o inteiro e mais amplo domínio de toda a arte" (Nachlass/FP 7 [126] KSA 7.184), confirmam tal suposição, e uma vez que, no mesmo momento de elaboração de $O$ nascimento da tragédia no espírito da música, ele se propõe a "[...] fortalecer o conceito do ingênuo e do sentimental" (Nachlass/FP 7 [172], KSA 7.206), tem-se justificada a intenção de relacionar ambas as obras-chave de ambos os Dichterphilosophen [filósofos poetas] do ponto de vista da crítica cultural.

Palavras-chave: Friedrich Schiller, Friedrich Nietzsche, crítica cultural, dicotomias culturais.

\footnotetext{
* Tradução de Saulo Krieger

** Departamento de Filologia Alemã e Filologia Eslava da Universidade Complutense de Madri, Madri, Espanha.

ORCID: https://orcid.org/0000-0001-6867-7972. Correio eletrônico: agimber@filol.ucm.es
} 
Gimber, A.

\section{Introdução}

A crítica cultural, se a entendemos em sentido restrito, não raro se faz uma crítica à dissociação entre natureza e cultura, sensualidade e moralidade. A partir das mudanças iniciadas pela Ilustração francesa, a civilização racionalista e desdeificada provocou no homem um sentimento de fragmentação, e isto não apenas pela superespecialização em funções determinadas de sua atividade profissional. Toda a comunidade estatal foi transformada num artifício (Machwerk, o chamaria Schiller) ou num intrincado mecanismo de relojoaria, com o qual o indivíduo já não podia se identificar. Toda a crítica cultural da Modernidade parte desta, digamos, constelação básica, e busca acercar-se dela por meio de pares de opostos. Os mais destacados vão desde a dicotomia entre anciens e modernes até a que se tem entre ingênuo e sentimento, e, referindo-nos já ao ensaio de Friedrich Schiller, Sobre a poesia ingênua e sentimental, também entre real e ideal [wirklich und ideal), liberdade e necessidade [Freiheit und Notwendigkeit) ou dever e querer [sollen und wollen]. Os românticos ampliaram essa série de dualidades até a variante do mitológico versus racional, e desse modo prepararam o caminho para Friedrich Nietzsche, que em sua obra $O$ nascimento da tragédia no espírito da música se valeu do dionisíaco e apolíneo como base de sua crítica cultural. Na via que conduz a Nietzsche, a dicotomia entre vontade e representação [Wille und Vorstellung], tal como se encontra em Schopenhauer, também poderia ser mencionada como etapa intermediária, mas entrar nessa toada significaria se distanciar demais do marco que estabelecemos aqui. E convém ressaltar de antemão que a crítica cultural como modo de reflexão da modernidade desde seus primórdios até hoje significa sobretudo certas atitudes e padrões de pensamento que não devem ser confundidos com conhecimentos, mas que permitem o processamento e a produção do conhecimento somente ao se tematizar, com a reivindicação de uma construção total, certos processos e situações, relações e condutas como indicadores 
Pensar em opostos: A crítica cultural de Friedrich Schiller e Friedrich...

de um mal-estar, tanto na atualidade quanto na história de uma decadência. Os críticos culturais de modo geral operam com imagens polarizadoras, caracterizadas por dicotomias. Neste sentido, Rousseau e Schiller são os precursores da crítica cultural, e Nietzsche mais não faz do que circunscrever-se em sua tradição, que será seguida, por exemplo, por Karl Jaspers ou Ludwig Klages. ${ }^{1}$

O ensaio Sobre poesia ingênua e sentimental, que segundo Walter Hinderer, em Schiller und kein Ende, constitui um documento fundador da modernidade literária, tem como pano de fundo uma tensão entre a situação político-social e questões de estética. E, conforme já constatado por Rüdiger Safranski², nele o amigo de Goethe trata de vincular o estético ao contexto social, fazendo-o, pois, também com as condições e possibilidades da arte de viver na modernidade. Seria possível acrescentar que cerca de oitenta anos antes de Friedrich Nietzsche, Schiller já era um analista e crítico da cultura, um "médico"3 para curar o que ele, e, de outro ponto de vista, os primeiros românticos alemães consideravam ser a crise daquele momento. Nietzsche empreende tarefa semelhante e, assim como Schiller, opera com dicotomias a fim de buscar o remédio para a dissonância no coração do mundo: "Se pudéssemos imaginar uma encarnação da dissonância - "e que outra coisa não será o ser humano? -, essa dissonância necessitaria, para poder viver, de uma ilusão magnífica que lhe pusesse um véu de beleza sobre a sua essência própria" (GT/NT 25, KSA 1.155). Essa ilusão, o véu da beleza (Schönheitsschleier) do idealismo, é o que propõe Schiller. Nietzsche reconhece a impossibilidade da ideia e trata de superá-la:

1 G. Bollenbeck, 2007.

2 R. Safranski, 2016, pp. 418-421.

3 R. Safranski, 2016, p. 409.

Cad. Nietzsche, Guarulhos/Porto Seguro, v.41, n.1, p. 63-82, janeiro/abril, 2020. | 65 
Gimber, A.

Não seria o caso de supor que, sob suas seduções idílicas, sob suas aduladoras artes alexandrinas, a tarefa suprema e que se deverá tomar por verdadeiramente séria da arte - redimir o olho de sua visão do espanto da noite e salvar o sujeito mediante o bálsamo curativo da aparência, da convulsão dos movimentos da vontade - há de se degenerar numa tendência vazia e dissipadora, à diversão? (GT/NT 19 , KSA 1.126).

Também por isso, com Gilbert Merlio ${ }^{4}$ vamos compartilhar a seguinte reflexão: Schiller não pode ser descrito como o precursor de Nietzsche, porém Nietzsche deve ser descrito como aperfeiçoador de Schiller. Segundo o crítico francês, ao mesmo tempo em que Schiller inaugura o século XIX, Nietzsche o encerrará na condição de crítico cultural, uma vez que a antítese de Schiller entre o ingênuo e o sentimental aparece como fase anterior ao dionisíaco e apolíneo. $\mathrm{O}$ filósofo considera que Goethe e Schiller não conseguiram “penetrar no cerne da essência helênica" (GT/NT 20, KSA 1.129) e, por isso, em O nascimento da tragédia no espírito da música Nietzsche estabelece uma nova dicotomia inerente ao mundo clássico, com importantes consequências para o seu tempo.

\section{Sobre a poesia ingênua e sentimental ante a Revolução Francesa}

A exemplo de muitos de seus contemporâneos, Friedrich Schiller viveu a Revolução Francesa a princípio com entusiasmo, porém logo se desencantou ante o regime de terror em Paris. Em 13 de julho de 1793, numa carta a seu mecenas de então, o duque de Augustenberg, perguntou-se se naquele momento histórico ainda poderia ser conveniente refletir e escrever sobre questões puramente poéticas, em vez de tomar iniciativas mais concretas no campo político. ${ }^{5}$ Esse aspecto nos parece importante, sobretudo porque

4 G. Merlio, p. 156.

5 F. Schiller, 1992, p. 259.

66 | Cad. Nietzsche, Guarulhos/Porto Seguro, v.41, n.1, p. 63-82, janeiro/abril, 2020. 
Pensar em opostos: A crítica cultural de Friedrich Schiller e Friedrich...

demonstra de que modo, depois de ter conquistado a cátedra de história na Universidade de Jena, em sua aula inaugural de 26 de maio de 1789, intitulada $O$ que significa estudar história universal e com que fim of fazemos? (Was heißt und zu welchem Ende studiert man Universalgeschichte?), Schiller ainda defende uma postura ilustrada de progresso e mostra-se convencido de que na história atuam os poderes da razão. Ainda confia na autodeterminação humana e em sua capacidade de socialização. Georg Bollenbeck ${ }^{6}$ expressa a suspeita de que Schiller só se converteria em cético por uma desilusão com o transcorrer da Revolução Francesa. Pois agora, em 1793, tem-se seu rechaço ao otimismo histórico universal e a transformação do historiador universal em crítico cultural.

Em carta a Wilhelm von Humboldt de 26 de outubro 17957, ou seja, em plena fase de elaboração de Sobre a poesia ingênua e sentimental, Schiller pergunta como um poeta poderia escrever poesia naquele momento. Avaliando aquele presente como fonte de mal-estar, adianta a Humboldt o que virá a ser a sua opção: o poeta tem de se retirar de sua própria realidade hostil e constituir um novo caminho com o auxílio dos mitos distantes, os da era idealista dos gregos. A mesma ideia aparece na carta de Schiller a Johan Gottfried Herder, de alguns dias depois, 4 de novembro. Queremos insistir na importância dos mitos, talvez de uma nova mitologia, que Schiller, tal qual os românticos, está a considerar neste texto, e que nos ocupará de novo quando falaremos de Nietzsche:

Pode-se [...] mostrar que nosso pensar e atuar, nossa vida e nosso operar burguês, político, religioso, científico [...] encontra-se em oposição à poesia. [...] Por essa razão, não conheço remédio para o gênio político, exceto o de se retirar do terreno do mundo real e de, em lugar de uma coalização, que lhe seria perigosa, concentrar-se em seus anseios de separação. Por isso, parece-me ser uma vantagem para ele o fato de formar seu próprio mundo e

6 Bollenbeck, 2007, p. 95.

7 F. Schiller, 1969, p. 83-86.

Cad. Nietzsche, Guarulhos/Porto Seguro, v.41, n.1, p. 63-82, janeiro/abril, 2020. | 67 
de, por meio dos mitos gregos, ser aparentado de uma época distante, estranha e idealista, uma vez que a realidade a partir dali só mesmo se conspurcaria. ${ }^{8}$

\begin{abstract}
Temos de compreender o ensaio de Friedrich Schiller a partir desse questionamento básico fundado na tensão entre natureza e cultura, antiguidade e modernidade, ideal e realidade, ao modo de uma invocação da arte apolínea. Sua importância reside na formulação de uma problemática que até o momento ninguém, não obstante os ensaios anteriores - do próprio Goethe, por exemplo ${ }^{9}$ - tinha expresso em tais dimensões, e que até hoje nos preocupa: a alienação do homem na sociedade moderna. É uma preocupação político-social, com claras consequências para o âmbito estético.
\end{abstract}

8 F. Schiller, 1969, p. 98 .

90 interesse pela arte chamada ingênua, isto é, a arte mais próxima do gênio da antiguidade, fez-se muito presente no pensamento da época. Não apenas se havia convertido em moda a volta à natureza - por exemplo, no entusiasmo segundo Rousseau -, como já os ilustrados Denis Diderot e Jean le Rond d'Alembert incluíram em sua Encyclopédie ou Dictionnaire raisonné um artigo sobre Naïveté que estabelece a problemática retomada por Schiller. Também Johann Georg Sulzer está entre os teóricos que vão abordar o ingênuo em sua Teoria geral das belas artes (Allgemeine Theorie der Schönen Künste), de 1771, manual de consulta e referência para todos os escritores do classicismo alemão. $\mathrm{O}$ ingênuo para ele tem origem numa alma dotada de sentimento, não depravada pela arte, pelo fingimento ou pela vaidade. Digno de nota é o fato de o início do ensaio de Schiller retomar precisamente essa ideia. E a lista poderia ser ainda maior: Christoph Martin Wieland, que morava próximo de Herder e Goethe em Weimar, já em 1753, com seu Tratado do ingênuo (Abhandlung vom Naiven), trouxe para o debate do momento a ideia da autêntica inocência da alma. O próprio Goethe publicou, em 1794, um ensaio intitulado "Em que medida a Ideia: que a beleza seja perfeição com liberdade, que possa ser empregada em naturezas orgânicas" (In wiefern die Idee: Schönheit sey Vollkommenheit mit Freyheit, auf organische Naturen angewendet werden könne). No West-östlicher Divan ele resume, e Schiller poderia subscrever a ideia de que "em todas as nações, a arte poética ingênua é a primeira, é a base de todo futuro; quanto mais natural e fresca ela aparecer, mais felizes serão as épocas posteriores". Praticamente todos os intelectuais da época se ocuparam do fenômeno: Karl Philipp Moritz em sua Doutrina dos deuses ou poesia mitológica dos antigos (Götterlehre oder mythologische Dichtung der Alten) ou Herder no Excerto de uma troca de cartas sobre Ossian e sobre as canções dos povos antigos (Auszug aus einem Briefwechsel über Ossian und die Lieder der alten Völker) e em Homero e Ossian (Homer und Ossian), declarando este último como representante moderno de um poeta ingênuo. Bem conhecido, ao menos em seu momento, foi também o texto de Christian Garve, de 1770, Consideração de algumas diferenças nas obras de antigos e novos escritores, em especial os poetas (Betrachtung einiger Verschiedenheiten in den Werken der ältesten und neuern Schriftstellern, besonders der Dichter). As questões giravam sempre em torno da relação entre natureza e cultura, em torno da tensão entre o natural e o artificial na arte, em torno do artista moderno alienado das origens da humanidade.

68 | Cad. Nietzsche, Guarulhos/Porto Seguro, v.41, n.1, p. 63-82, janeiro/abril, 2020. 
Pensar em opostos: A crítica cultural de Friedrich Schiller e Friedrich...

Schiller redigiu a versão definitiva de Sobre a poesia ingênua e sentimental entre setembro de 1795 e janeiro de 1796, ao que foi publicando o ensaio em três partes em sua própria revista, Die Horen. No texto programático da revista, insistiu na eliminação da "Scheinwand" (fronteira fictícia), "[...] que separa o belo mundo dos eruditos para prejuízo de ambos", e nisso postulou a "introdução de um conhecimento profundo na vida social e do gosto pelas ciências". ${ }^{10}$ Também aí vemos sua postura crítica, que data de anos anteriores e vai mais além do mal-estar causado pela fase do terror da Revolução Francesa. Queremos recordar apenas o juízo emitido por Karl von Moor em sua obra dramatúrgica da juventude, Os ladrões (Die Räuber) (1781): "Enfastia-me nosso século, insaciável de tinta, quando leio Plutarco, sobre as vidas dos grandes homens". E mais adiante escreve: "Vai-te! Vai-te com este débil século de castrados que mais não servem do que para ruminar as façanhas do passado e desolar os heróis da Antiguidade e estropiar com a tragédia". ${ }^{11}$

Eis aqui outro aspecto da crítica cultural de Schiller do qual Nietzsche se acercará.

\section{Outra forma de Querelle}

Os pensamentos de Schiller, a se crer no que confessa a Wilhelm von Humboldt, não estão relacionados com a querela francesa, por mais que na nota 9 do próprio ensaio Sobre poesia ingênua e sentimental ele insista em que a diferença entre ingênuo e sentimental não coincide com a que se tem entre antigos e modernos. A chamada Querela dos antigos e modernos (Querelle des Anciens et Modernes), durante mais de um século teve consequências nos círculos intelectuais e artísticos de toda a Europa. Ela trata, em resumo, da questão sobre se era possível ou não o acesso estético ao presente por meio da antiguidade clássica.

10 F. Schiller, 1958, p. 206.

11 F. Schiller, 1958, p 21.

Cad. Nietzsche, Guarulhos/Porto Seguro, v.41, n.1, p. 63-82, janeiro/abril, 2020. | 69 
Gimber, A.

Schiller não insiste na contradição entre tradição e progresso, como se discute na França absolutista, com claras implicações políticas, mas opera uma incursão no estético e pergunta se, em que tanto pese a nossa atitude reflexiva, poderíamos recuperar a conexão entre natureza e cultura. Na Querelle surge, e isto é o que importa aqui, a dicotomia entre os costumes selvagens, arcaicos, porém poéticos, de uma época de êxitos, e a bela natureza de um conceito civilizado e polido pela razão. Essa oposição, quer me parecer, remete mais a Friedrich Nietzsche do que ao próprio Schiller. É verdade que Schiller se afasta desse posicionamento, e a oposição agora se dá menos entre antigos e modernos e mais entre imitação da natureza e reflexão em torno da realidade que nos rodeia. Ainda assim, mais adiante, num momento de duras críticas ao poeta Klopstock, de súbito ele iguala o ingênuo ao antigo e o sentimental ao moderno:

Eu queria mostrar a diversidade do caminho percorrido até uma mesma meta por poetas antigos e modernos, ingênuos e sentimentais; queria mostrar que se uns nos tocam pela natureza, pela individualidade e pela viva sensorialidade [Sinnlichkeit], outros, valendo-se de ideias e de uma elevada espiritualidade [Geistigkeit], revelam influxo não menos poderoso sobre nossas almas, ainda que ele seja menos amplo. ${ }^{12}$

É importante a dualidade que Schiller aqui faz desdobrar entre natureza, individualidade e a viva sensorialidade, por um lado, e ideias e uma elevada espiritualidade, por outro. Como resultado de sua argumentação, poder-se-ia talvez chegar a uma nova dicotomia, falando-se da individualidade como traço característico dos antigos e da idealidade como força dos modernos:

Poetas dessa estirpe ingênua já não convêm de todo a um século artificioso. Tampouco são já quase possíveis nele; em todo caso, eles o são unicamente se se mantiverem apartados de sua época e se um destino favorável os vier

12 F. Schiller, 2002, p. 58.

70 | Cad. Nietzsche, Guarulhos/Porto Seguro, v.41, n.1, p. 63-82, janeiro/abril, 2020. 
proteger de seu influxo mutilador [...] Trazem marcado na fronte o selo de seu senhorio; nós, em compensação, queremos ser acalantados e levados pelas musas. Os críticos, verdadeiros guardas fronteiriças do gosto, os odeiam porque eles transtornam os limites que prefeririam suprimir $[\ldots]$... ${ }^{13}$

Mais além das coincidências dessa citação com o sexto capítulo do Heinrich von Ofterdingen, de Novalis, queremos ressaltar que Schiller encontra-se consciente da impossibilidade de voltar atrás para superar a suposta crise. Schiller não busca soluções como fazem os franceses, isto é, a nova era para ele não pode ser a de uma literatura dotada de razão, como propõe já em 1715 o abade Jean Terrasson. O que o pode interessar na Querelle é o seu horizonte de crítica civilizatória, a experiência da alienação do ser humano como ser imperfeito (Mängelwesen), ideia esta que será retomada por Jean Jacques Rousseau. Tanto Schiller como antes dele Winckelmann articulam seus impulsos de crítica cultural diante do pano de fundo da Querelle, com a diferença que Schiller resume exatamente quando escreve que "o sentimento de que aqui se trata não é, pois, o que os antigos temiam; na verdade ele coincide com o que nós temos para com os antigos." 14

Nietzsche, na mesma direção, insiste em que a imitação tem de ser abandonada pela criação. Num fragmento póstumo de 1875 , ele escreve que:

Toda imitação mais não é do que um fenômeno artístico, isto é, um fenómeno que se dirige às aparências; algo vivo por imitação pode adotar modos, pensamentos etc., mas não pode produzir nada. Uma cultura que imita a cultura grega não pode produzir nada. $\mathrm{O}$ criador pode tomar de empréstimo e se alimentar por toda a parte. É assim que só poderemos obter algo dos gregos como criadores. (Nachlass/FP 7 [1], 1875, KSA 8.121)

13 F. Schiller, 2002, p. 32.

14. Schiller, 2002, p. 27.

Cad. Nietzsche, Guarulhos/Porto Seguro, v.41, n.1, p. 63-82, janeiro/abril, 2020. | 71 
Gimber, A.

O poeta moderno é sentimento porque não imita, e sim medita (Schiller usa a palavra reflektieren) sobre a impressão que lhe produzem os objetos. E o poeta sentimental tem sempre de ver as impressões com duas representações e sentimentos em embate, com a realidade como limite e com sua ideia como o infinito, e a emoção mista que provoca sempre dará testemunho dessa dupla fonte. As representações e os sentimentos em embate lhe obrigam a refletir, e refletindo ele trata a realidade de três maneiras distintas: de maneira satírica, quando representam a distância da realidade do ideal; em forma de elegia, ao que deseja lamentar essa distância; em forma idílica, por fim, sendo esta, sempre segundo Schiller, uma forma especial de elegia, menos tristeza pela ausência do ideal e mais a expressão de certa alegria pelo ideal em que a realidade aparece como natureza.

$\mathrm{E}$ aqui de novo podemos ver antecipadas as ideias de Nietzsche. Friedrich Nietzsche, como é sabido, aparentemente não tinha Schiller em muito alta conta como pensador filosófico, e isto ele sugere, por exemplo, nas várias alusões de $O$ andarilho e sua sombra. Na obra que aqui nos ocupa, ele insiste em que a imagem da antiguidade proporcionada pelos clássicos alemães na tradição de Winckelman fez-se por demais reduzida, já que lhe faltava o componente dionisíaco:

Mas aqui não se deve silenciar quanto a que essa harmonia, mais ainda, essa unidade do ser humano com a natureza, contemplada pelos seres humanos com tanta nostalgia, para a qual Schiller pôs em circulação o termo técnico "ingênuo", de modo algum é um estado tão simples, evidente por si só, inevitável, por assim dizer, com o qual teríamos de nos encontrar na porta de toda a cultura, como se fosse um paraíso da humanidade (GT/ NT 21, KSA 1.37).

Não obstante, o crítico cultural, o Schiller que mete o dedo na ferida do mal-estar da cultura, efetivamente atinge a afirmação de Nietzsche. Contudo, e aqui se tem uma das diferenças fundamentais 
Pensar em opostos: A crítica cultural de Friedrich Schiller e Friedrich...

entre os pensadores, para o filósofo a ingenuidade não é produto da natureza, mas sim da cultura, uma vez que “a 'ingenuidade’ homérica há de ser concebida como vitória completa da ilusão apolínea (GT/ NT 21, KSA 1.37)". Ou seja, a antítese entre ingênuo e sentimental parece-lhe uma fase prévia imperfeita em relação à sua própria, a antítese entre apolíneo e dionisíaco.

Sobre essa base, passemos a uma visão mais aproximada, por crer haver mais afinidades entre Schiller e Nietzsche do que as que convencionalmente se aceita. Mais além do Dichterphilosoph (poeta flósofo), que é aplicável a ambos, já no poema Os deuses da Grécia de Schiller encontram-se, segundo Safranski ${ }^{15}$, mais elementos dionisíacos do que à primeira vista se percebe. Schiller apresenta uma trágica imagem dionisíaca do homem moderno, que exclui a ingenuidade ou a serenidade grega. Nietzsche a encontra já na Grécia antiga. Por outro lado, os três gêneros que Schiller estabelece em Sobre a poesia ingênua e sentimental - sátira, elegia e idílio correspondem às três variantes de história que Nietzsche introduz em suas Considerações extemporâneas: crítica, antiquária, monumental. Seria interessante explorar a questão sobre como as dicotomias aqui e possivelmente em outros casos são substituídas por tríades. Não obstante, isso iria além do alcance deste artigo.

Conforme lemos num fragmento póstumo do início do ano de 1871, ou seja, em plena fase de redação de $O$ nascimento da tragédia no espírito da música, Nietzsche outorga a Schiller o mérito de ter sido o primeiro a se dar conta de que a origem da lírica se enraíza no dionisíaco, insistindo em sua origem na música. Passa a impressão de estar lutando com a dicotomia schilleriana para poder compreendêla: "A ocultação completa por meio de mecanismos enganosos é 'ingênua', a ruptura desses mecanismos, que requer a vontade de uma quimera, é "sentimental"' (Nachlass/FP, 7 [172], 1870/71, KSA 7.206), como escreve em outro fragmento, do período entre 1870 e

15 Safranski, 2016, p. 288.

Cad. Nietzsche, Guarulhos/Porto Seguro, v.41, n.1, p. 63-82, janeiro/abril, 2020. | 73 
Gimber, A.

1871. A ofuscação completa por mecanismos enganosos é "ingênua", o desgarrar-se de tais mecanismos, que requer a vontade de uma rede de emergência, é "sentimental".

Muito se pode obter do contraste entre dionisíaco e apolíneo. $\mathrm{O}$ ponto fulcral não consiste na distinção dos poderes da arte, e sim na conexão de sua dualidade no pensamento de uma necessidade mútua. Em contraste com a versão da dupla estética de Schiller, Nietzsche descreve uma espécie de duplo impulso artístico.

\section{O apolíneo e o dionisíaco}

Também o dadaísta Hugo Ball ${ }^{16}$, em sua tese de doutorado inacabada sobre Friedrich Nietzsche, entende $O$ nascimento $d a$ tragédia no espírito da música como um texto cultural e o corrobora citando o fragmento: "Esta é a nossa condição humana moderna: portanto, desfrutemo-la como seres morais. $\mathrm{O}$ mundo grego acabou". $\mathrm{O}$ que se pode aprender com os gregos, pergunta-se, se se parte de seu mundo alegre e harmônico a ocultar seu lado obscuro? E, referindo-se a Schiller, afirma que só mesmo nessas circunstâncias a arte ingênua poderia ser dotada de natureza. Não obstante, assente com Nietzsche quando diz que

todo o nosso mundo moderno encontra-se preso à rede da cultura alexandrina e tem como ideal o ser humano teórico, equipado com as forças cognitivas supremas, que trabalha a serviço da ciência, um tipo humano cuja imagem primordial e cujo antecessor fundacional é Sócrates" (GT/NT 18, KSA 1. 116).

Precisamente nessa observação Ball vê uma de suas grandes consequências culturais, enquanto Nietzsche, diríamos, dá continuidade e supera Schiller.

16 H. Ball, 2008. In: https://www.textlog.de/hugo-ball-nietzsche-basel.html

74 | Cad. Nietzsche, Guarulhos/Porto Seguro, v.41, n.1, p. 63-82, janeiro/abril, 2020. 
Pensar em opostos: A crítica cultural de Friedrich Schiller e Friedrich...

A atração de Nietzsche pelos gregos também vive, como a de Schiller, do desejo sentimental do homem moderno de recuperar o que foi perdido com a antiguidade. Porém, e aqui está a diferença, seus gregos conhecem os horrores da existência e podem suportá-la porque afirmam a vida em sua arte e no mundo dos deuses. $\mathrm{O}$ que os gregos estão mostrando é, segundo Nietzsche, uma vontade de viver. Em $O$ nascimento da tragédia no espírito da música, em particular nos capítulos 7 e 8, pode-se encontrar a antítese fundamental entre a natureza e civilização. A natureza não é entendida como em Rousseau, como pré-moralmente neutra, ou, como no caso de Schiller, ao modo uma chave de humanidade e moralidade. A natureza aqui significa a anarquia amoral dos instintos, a sexualidade e a vida. No Sátiro, o arquétipo do homem e o "do coreuta dionisíaco" (GT/ NT 7, KSA 1.55), tem-se uma naturalidade que é incompatível com os gregos brandos (diria Nietzsche), com os gregos da harmonia e da moralidade, da humanidade e da razão, da ordem e da forma, gregos assim resultantes do projeto de seus contemporâneos. A esse respeito, seja dito de passagem, surge a maior crítica à disciplina, à época personificada por Ulrich von Wilamowitz-Möllendorf, contra a tese do jovem catedrático em filologia clássica. Nietzsche volta-se menos contra o ideal grego dos clássicos e mais contra o de seus contemporâneos, contra "a miserável idealização dos gregos, que o jovem 'com educação clássica' leva da vida como recompensa por seu adestramento na escola secundária" (GD/CI, O que devo aos antigos 2, KSA 6.156), como afirma no segundo parágrafo de seu ensaio intitulado "O que devo aos antigos".

Tal qual o sentimental e ingênuo, o apolíneo e dionisíaco não apenas representam duas formas estéticas de expressão que se manifestam em obras literárias, mas representam também certas forças vitais, sejam elas forças de distância e individualidade ou forças de embriaguez e coletivismo. Esse coletivismo relacionado à força integradora da nova mitologia romântica desemboca na arte de 
Gimber, A.

Wagner, na qual cobra ainda maior intensidade como crítica cultural. O que importa nesse contexto é que a interpretação por Nietzsche da cultura grega baseia-se num emocionante vínculo fraterno entre o apolíneo e o dionisíaco. E quando introduz o dionisíaco como uma representação da ausência de forma, do mito, da proximidade com a natureza e com o instinto, então ele dá um passo mais além, o mais radical que pudemos observar em Friedrich Schiller.

Tanto Sobre poesia ingênua e sentimental como $O$ nascimento da tragédia no espírito da música baseiam-se em uma visão, digamos, sentimental do mundo como presente deficiente. Antes de chegar a Nietzsche, essa visão de Schiller fez-se sedimentar ao longo do século XIX mediante perspectivas da antropologia biológica, na qual a natureza é impulso, sexualidade e vontade. A visão de Schiller, segundo a tese de Riedel, permitiu a Nietzsche superar o pessimismo schopenhaueriano tendo-se o amor fati como dobradiça. Nietzsche [...] deseja mais fazer o caminho oposto, até que uma afirmação dionisíaca do mundo tal como é $[. .$.$] - queira o ciclo eterno [...$ minha fórmula para tal é o amor fati $[\ldots] .{ }^{17}$ Por um lado, trata-se da aceitação do que é natural e inevitável, como algo necessário, do que nos nutrimos e em cujo entorno evoluímos. Por outro lado, Nietzsche, fazendo referência à forma de vida grega da antiguidade, mostra que se considerava prioritário viver o presente com entrega. Basta que vejamos o tempo como uma linha reta para que nos desloquemos; não obstante, por Nietzsche ele é considerado como circular, conceito que assim descreve com a expressão eterno retorno. $\mathrm{O}$ além-do-homem (Übermensch) é o único capaz de sair do círculo fechado do eterno retorno, e nesse contexto não caberia o conceito de evolução.

Com isso queremos afirmar que a versão de Nietzsche da antiga Grécia caracteriza-se não apenas pelo descobrimento do dionisíaco, e sim esconde mais facetas. Entre outras encontra-se a descrição da decadência socrática. Como racionalista, o homem

17 Riedel, 2011, p. 174.

76 | Cad. Nietzsche, Guarulhos/Porto Seguro, v.41, n.1, p. 63-82, janeiro/abril, 2020. 
Pensar em opostos: A crítica cultural de Friedrich Schiller e Friedrich...

socrático é o traidor da vida, e Nietzsche diagnostica de maneira análoga a decadência de nossa moderna cultura. A divisa do Sócrates homem teórico poderia se resumir com a fórmula "conhecimento é virtude e virtude é felicidade". Na realidade, tem-se aí o lema da Ilustração. Depois da experiência da Revolução Francesa e das guerras revolucionárias, Schiller crê poder constatar seu fracasso. Suas cartas sobre a educação estética do homem iniciam-se com a pregunta sobre por que tal barbárie é possível numa época tão ilustrada. Segundo Kant, para muitos surge a pergunta sobre como se pode tornar a razão mais atraente, e portanto mais efetiva. Por meio de uma remitificação, pensam os autores do programa de sistema mais antigo do idealismo alemão. Por meio de uma educação estética que reconcilie as duas naturezas humanas, a saber, a inclinação (Neigung) e o dever (Pficht), propõe Schiller.

Nietzsche retoma o legado da crítica cultural assinalando também o mal da civilização tal como tratado até agora. Sua crítica cultural aumenta em razão da experiência do século XIX, que é a experiência do capitalismo triunfante, da irrefreável massificação e difusão da tecnologia. Nesse contexto, a transposição consciente das fronteiras como característica central da experiência do mundo dionisíaco oferece a perspectiva da reconciliação com a natureza, pela qual tanto ansiaram Schiller e os românticos, mas que agora passa por complicações, até pelo fato de Nietzsche ter sacado os lados, digamos, obscuros desse tão idealizado mundo clássico. Os gregos viveram num mundo heroico de sensualidade e crueldade, num mundo que não pode ser considerado nem um estado feliz da natureza nem uma idade de ouro civilizadora. Em razão da crueldade real de seu mundo helênico, Nietzsche só pode pensar na reconciliação entre os seres humanos, por um lado, e entre os seres humanos e a natureza, por outro, no estado dionisíaco. Com essa ideia, a passagem culturalcrítica de um passado embelezado para um futuro promissor, passando por um mal presente, se relativiza. Como a Arcádia perdida só se 
Gimber, A.

manifesta esteticamente, não pode haver um Elíseo como alternativa social. A Grécia dionisíaca é então o ponto de partida de Nietzsche para um diagnóstico cultural-crítico do presente, mas a saída só pode ser buscada na dimensão do além-do-homem. Este é o ponto de partida para outro capítulo de crítica cultural que ora só podemos mencionar, e de modo superficial, nas conclusões deste artigo.

\section{Conclusão}

Voltemos às dicotomias. A crítica cultural continua a manobrar nesta categoria até em nossos dias. Em fins do século XIX inicia-se o que se tornou conhecido como revolução conservadora. Lagarde, Langbehn ou Chamberlain, para mencionar apenas os mais conhecidos representantes que, com o procedimento formal dos opostos, fazem um diagnóstico da decadência de seu tempo. Introduzem combinações opostas, como cultura versus civilização, vida versus rigidez ou petrificação, idealismo versus materialismo, individualidade versus massa, comunidade versus sociedade e até mesmo masculinidade versus feminilidade ou afeminação. São posturas que levam a uma radicalização da crítica cultural nos primórdios do século XX, e seria interessante aprofundar a pergunta sobre quantos opostos entre os citados baseiam-se no já construído por Nietzsche. O certo é que os representantes da crítica cultural, no marco da revolução conservadora, inscrevem-se na tradição nietzschiana, e em muitas ocasiões proclamam seu modelo. Não obstante, não se pode reduzir a crítica cultural de Nietzsche a uma simples dicotomia, como esperamos ter podido aclarar, no que diz respeito ao apolíneo e dionisíaco. Não se faria justiça a Nietzsche se não se mencionasse, por fim, que foi precisamente ele quem superou as dicotomias, o pensamento bipolar sendo talvez o primeiro no Ocidente a romper com a mais radical das dicotomias, a de corpo e alma. Insinua-o já o início da seção 25 da obra de que aqui nos ocupamos prioritariamente, O nascimento da tragédia no espírito da música:

78 | Cad. Nietzsche, Guarulhos/Porto Seguro, v.41, n.1, p. 63-82, janeiro/abril, 2020. 
Pensar em opostos: A crítica cultural de Friedrich Schiller e Friedrich...

Se pudéssemos imaginar uma encarnação da dissonância - e que outra coisa é o homem? - tal dissonância precisaria, a fim de poder viver, de uma ilusão magnífica que cobrisse com um véu de beleza a sua própria essência. Eis o verdadeiro desígnio artístico de Apolo: sob o seu nome reunimos todas aquelas inumeráveis ilusões da bela aparência que, a cada instante, tornam de algum modo a existência digna de ser vivia e impelem a viver o momento seguinte. (GT/NT 25, KSA 1.155)

Nas imediações temporais de $O$ nascimento da tragédia no espírito da música, Nietzsche concebeu os primeiros esboços de Sobre verdade e mentira no sentido extramoral, (neste em que, por certo, se dá outra dicotomia, a do homem racional versus homem intuitivo), escrito publicado postumamente, no qual se tematiza uma teoria da metáfora e do impulso da ilusão linguística em geral. E nesse contexto, Nietzsche enfatiza que o pensamento mítico dos gregos não funciona com a dicotomia verdadeiro versus falso, mas sim com sequências de metáforas que, em âmbito narrativo, trazem consigo suas próprias estruturas de significação. Essa observação é decisiva para o pós-estruturalismo, este que, quando insiste no pensamento da ambiguidade e da indecisão, quando questiona o pensamento categorizador da modernidade, isto é, o pensamento em dicotomias, seu ponto de partida é precisamente a Nietzsche. A crítica à tradição científica e principalmente filosófica do pensamento iniciada com Nietzsche e suscitada pela teoria do discurso francês mais recente abre um novo espaço de experiência e, portanto, dirige-se contra as categorias centrais de referência como a origem, o significado e o tema. $\mathrm{O}$ pensamento em binômios representa um paradigma do moderno que se baseia em exclusões e é substituído pelo reconhecimento das ambivalências, das ambiguidades irreversíveis da existência humana. Isto é exatamente o que Nietzsche já havia pré-pensado. 
Gimber, A.

\title{
Thinking in Opposites: Cultural Criticism of Friedrich Schiller and Friedrich Nietzsche
}

\begin{abstract}
Friedrich Nietzsche's opinion about Friedrich Schiller is well known and culminates in 1888 in the disqualification "Schiller: oder der Moral-Trompeter von Säckingen" (KSA 6.111), but at the same time it is recognized that his considerations are contradictory and that they change in the different moments of his productive life. Nicholas Martin's study from 1996 marks a caesura in this subject by refuting the widespread view that only the young Nietzsche experienced admiration for Schiller and that there was a growing distance afterwards. Nietzsche's debt to Schiller, according to Martin, is constant and is manifested above all in his reception of the aesthetic letters. We would like to demonstrate in the tradition of Wolfgang Riedel that the essay Über naive und sentimentalische Dichtung is equally or even more important in this context, especially when it is approached from the standpoint of cultural criticism. Several statements by Nietzsche, such as the one formulated in 1870 "Ich bin nicht im Stande, jene herrliche Schillersche Terminologie auf das ganze weiteste Bereich aller Kunst anzuwenden" (KSA, 7, 184) confirm this assumption, and when, at the very moment when Die Geburt der Tragödie aus dem Geist der Musik was being prepared, Nietzsche proposed that the "[...] Begriff des Naiven und des Sentimentalistischen ist zu steigern" (KSA, 7, 206), the attempt to link both key works of the two Dichterphilosophen from the point of view of cultural criticism is justified.
\end{abstract}

Keywords: Friedrich Schiller, Friedrich Nietzsche, Cultural Criticism, Cultural Dichotomies.

\section{Referências}

BALL, H. Nietzsche in Basel. Eine Streitschrift. In: https://www.textlog.de/hugoball-nietzsche-basel.html, 2008 (útimo acceso 21-01-2020).

Bollenbeck, G. Eine Geschichte der Kulturkritik von Rousseau bis Günther Anders. München: Beck, 2007.

Hinderer, W. Schiller und kein Ende. Metamorphosen und kreative Aneignungen. Würzburg: Königshausen \& Neumann, 2009. 
Pensar em opostos: A crítica cultural de Friedrich Schiller e Friedrich...

Luserke-Jaqui, M. Friedrich Schiller. Tübingen/Basel: Narr/Francke, 2005.

Martin, N. Schiller and Nietzsche, Untimely Aesthetics. Oxford: Clarendon Press, 1996.

Merlio, G. La crise de la modernité selon Schiller. In: Revue Germanique Internationale, vol. 22, 2004, pp. 145-160.

NIETZSCHE, F. Sämtliche Werke. Kritische Studienausgabe (Band 1). Herausgegeben von Giorgio Colli und Mazzino Montinari. München/Berlin/ New York: Deutscher Taschenbuch Verlag de Gruyter, 1999.

. Sämtliche Werke. Kritische Studienausgabe (vol. 6). COLLI \& MONTINARI (org.). München/Berlin/New York: Deutscher Taschenbuch Verlag de Gruyter, 1999.

. Sämtliche Werke. Kritische Studienausgabe (vol. 7). COLLI \& MONTINARI (org.). München/Berlin/New York: Deutscher Taschenbuch Verlag de Gruyter, 1999.

. Sämtliche Werke. Kritische Studienausgabe (vol. 8). COLLI \& MONTINARI (org.). München/Berlin/New York: Deutscher Taschenbuch Verlag de Gruyter, 1999.

Riedel, W. Homo natura. Literarische Anthropologie um 1900. Würzburg: Königshausen \& Neumann, 2011.

Safranski, R. Schiller oder die Erfindung des deutschen Idealismus. Frankfurt/ Main: Fischer, 2016.

Schiller, F. Briefwechsel. Schillers Briefe 1.3.1790-17.5.1794. Nationalausgabe (Band 26). Edith Nahler e Horst Nahler (org.). Weimar: Verlag Hermann Böhlaus Nachfolger Weimar, 1992.

. Briefwechsel. Schillers Briefe 1.7.1795-31.10.1796. Nationalausgabe (vol. 28). Oellers, N. (org.). Weimar: Verlag Hermann Böhlaus Nachfolger Weimar, 1969.

. Die Räuber. Nationalausgabe (vol. 3). STUBENRAUCH, H. (org.). Weimar: Verlag Hermann Böhlaus Nachfolger Weimar, 1958. 
Gimber, A.

. Über naive und sentimentalische Dichtung. Herausgegeben BERGHAN K. L. (org.). Stuttgart: Reclam, 2002.

. Vermischte Schriften. Nationalausgabe (vol. 22). MEYER, H. (org.). Weimar: Verlag Hermann Böhlaus Nachfolger Weimar, 1958.

Schmidt, B. M. Denker ohne Gott und Vater. Schiller, Schlegel und der Entwurf von Modernität. Stuttgart / Weimar: Metzler, 2001.

Sommer A. U. / Kaufmann S. (org.). Nietzsche und die konservative Revolution. Berlin: De Gruyter, 2018.

Stuckrad, K. v. Die Seele im 20. Jahrhundert. Eine Kulturgeschichte. Paderborn: Fink, 2019.

Szondi, P. "Das Naive ist das Sentimentalische. Zur Begriffsdialektik in Schillers Abhandlung". In: Euphorion, vol. 66, 1972, pp. 174-206.

Tschierske, U. Vernunftskritik und ästhetische Subjektivität. Studien zur Anthropologie Friedrich Schillers. Tübingen: Niemeyer, 1988. 